\title{
China: el nuevo estado de la Reforma
}

Alejandro Pescador*

DOI: $10.32870 /$ mycp.v7i23.630

\author{
Reseña del libro: Chi Fulin, China: the New Stage of Reform,
} Foreign Language Press, Pekín, China, 2004, 328 pp.

$\mathrm{E}$ l profesor Chi Fulin, nacido en 1951 en la Provincia de Shandong - tierra de origen de Confucio-, obtuvo una maestría en la Escuela de Cuadros del Partido Comunista Chino. Ha sido profesor de esta misma institución, así como de la Universidad Nacional de Tecnología Militar. Entre 1988 y 1993 fue director del Instituto de Reforma y Desarrollo, con sede en la isla de Hainan, en el extremo sur del territorio chino. Aún funge como vicepresidente del consejo directivo del instituto. Ha dado clases en las universidades de Pekín, Nanjing y Xiamen.

Hay que mencionar que este instituto es un centro de estudios estratégicos y de consultoría vinculado a la Comisión Nacional de Reforma y Desarrollo de China, el superministerio que diseña y dirige el desarrollo económico del país.

En este libro del profesor Chi Fulin, los efectos de la epidemia de neumonía atípica que asoló a China entre 2002 y 2003 sirven de punto de partida para analizar las grandes líneas de la actual estrategia de desarrollo emprendida por Pekín. Las nuevas prioridades en esta etapa buscan poner atención en el desarrollo social; facilitar el ejercicio informativo de los medios de comunicación en todo lo relativo a emergencias nacionales; reestructurar el sistema de salud, y dotar al sistema de administración pública de mejores mecanismos para rendir cuentas. Cada uno de estos puntos recoge una diversidad de voces que surgieron durante la epidemia y que llamaron la atención sobre los problemas marginalizados por la prioridad dedicada al desarrollo económico.

* Consejero de la Embajada de México en China.
El libro se divide en seis capítulos: a) Los avances y retos de esta nueva etapa de la reforma; b) Las reformas al interior del aparato gubernamental y el surgimiento de las organizaciones no gubernamentales; c) El ingreso a la Organización Mundial del Comercio y el nuevo capítulo de la apertura al exterior; d) Una nueva política integral para el campo; e) Tópicos recientes en infraestructura y el sector servicios; f) La formación del sistema empresarial y el plan para hacer de los empleados copropietarios de las empresas.

a) Los avances y retos de esta nueva etapa de la reforma. Después de su ingreso a la омc, China debió enfrentar una nueva serie de retos en los ámbitos económico y social. ${ }^{1}$ Así, por ejemplo, "la economía socialista de mercado con características chinas" ha generado efectos indeseados como la creciente polarización del ingreso, sobre todo entre la población urbana y la rural. Para corregir este desequilibrio, el profesor Chi sugiere, por un lado, reducir las cargas fiscales que deprimen el ingreso de los campesinos. Pero, por otro lado, recomienda que el punto focal de la reforma económica estructural se ubique en el segmento de ingresos medios.

Respecto a la reforma del sistema tributario que se aplica en el campo, la nueva administración gubernamental, que inició su gestión en marzo de 2003, ya ha dado pasos decisivos a favor de los campesinos. ${ }^{2}$ Por lo que se refiere a la promoción de los segmentos medios, dicha propuesta ya se encuentra en marcha desde la celebración del XVI Congreso del PC, de noviembre de 2002, cuando Jiang Zemin, saliente secretario general, anunció la meta de promover "una sociedad moderadamente acomodada" (xiao kang), con un nivel 
de vida medio que, además de permitir la satisfacción de las necesidades esenciales, pondrá a su alcance el disfrute de oportunidades que de manera creciente ofrece el desarrollo económico del país.

Tras su acceso a la omc, China no sólo ha cumplido con sus compromisos ante la organización, sino que en algunos aspectos ha rebasado las expectativas de apertura. Tal adelanto se debe a que la dirigencia china evaluó con antelación los impactos que tendría en la economía nacional la participación en este esquema del comercio mundial y decidió tomar todas las medidas a su alcance para estar en condiciones de competir en la medida en que se cumplieran las etapas del calendario de apertura acordado con la omc e incluso antes.

Una de las prioridades en este ámbito se refiere al aumento de la competitividad de las empresas mixtas y privadas. Para esta nueva etapa de la reforma, las prioridades, explica el profesor Chi Fulin, han de abocarse a los objetivos sociales del desarrollo y a un ejercicio de la administración pública dentro del marco jurídico vigente en el país. Este último aspecto apunta sobre todo a la reducción drástica de los márgenes de discrecionalidad en las decisiones gubernamentales.

Aunado a lo anterior, el autor de este libro urge a corregir en definitiva el problema de la cartera vencida de los bancos estatales chinos, los cuales, entre otras dificultades, aún no cuentan con mecanismos confiables para comprobar la capacidad de pago de los solicitantes de crédito. ${ }^{3}$

No menos importancia reviste la observación del profesor Chi para aplicar nuevas medidas de supervisión al uso del "poder administrativo", tanto para mejorar la eficiencia económica, como para combatir la corrupción. En este aspecto se critica sobre todo que, pese a que desde un principio de la reforma se dictaron medidas para evitar la duplicidad de funciones entre el gobierno y las empresas, este problema aún persiste. En este tenor, conviene tener presente que a principios de 2005, unos 8000 cuadros del PC debieron renunciar a los puestos que simultáneamente desempeñaban en diversas empresas.

Según China: the New Stage of Reform, la reforma estructural y la innovación institucional constituyen prioridades tanto para responder a las necesidades internas como a los retos que presenta la integración a la economía mundial. Chi hace un llamado a la reforma de los derechos de autor, aunque este aspecto ya cuenta con todo un nuevo marco jurídico a partir de marzo de 2004, al promulgarse las Disposiciones Regulatorias de Protección de los Derechos de la Propiedad Intelectual. Por lo que respecta al sistema de propiedad privada, el autor ponía de relieve en octubre de 2001 la necesidad de protegerla, algo que se volvió realidad en China a partir de la reforma constitucional de marzo de 2004 que protege la propiedad legítimamente adquirida (artículo 13 de la Constitución de la República Popular China).

b) Las reformas al interior del aparato gubernamental y el surgimiento de las organizaciones no gubernamentales. El ingreso de China a la omc ha entrañado un proceso de grandes ajustes institucionales. Ahora el gobierno chino entra ya a una nueva fase de cambios en cuanto a sus propias funciones. Se acentuará la separación entre agencias guber- 
namentales y la administración de las empresas estatales. En todo caso, el Estado mantendrá su carácter de rector de la economía. Chi predice un desarrollo en las políticas de desarrollo social y al mismo tiempo una actuación del gobierno apegada a derecho, ante la plena expansión de las inversiones de empresas privadas tanto chinas como extranjeras. En cuanto a las ONG, el libro considera sólo a las organizaciones empresariales, los institutos de investigación científica y las asociaciones. Todas ellas se encuentran "bajo el liderazgo político del PC" (p. 95). Aparentemente en este categoría no se incluyen las $\mathrm{ONG}$, que se ocupan de temas como el medio ambiente y los derechos humanos, etcétera.

c) El ingreso a la Organización Mundial del Comercio y el nuevo capítulo de la apertura al exterior. El acceso a la oMc ha favorecido las políticas de reforma y apertura en China. Esto ha permitido al país absorber amplios volúmenes de inversión extranjera directa, nuevas tecnologías, capacitación, entre otros. El profesor Chi Fulin manifiesta su optimismo de que la IED se extienda a todas las regiones del país y genere ahí resultados positivos para las economías locales. De esta forma, la expansión de la economía china, indica el autor, beneficiará a otros países, principalmente a los asiáticos, por su influencia estable y también por el abatimiento de los costos de producción.

El ingreso a la omc permite a China interactuar con otros miembros de la organización para negociar la liberalización de algunos sectores particulares. ${ }^{4}$ Sin embargo, la dirigencia china tiene presentes los riesgos que implica la inserción de China en la economía mundial. Después de atender los problemas de la cartera vencida de los bancos estatales, mencionada ya líneas arriba, el país se prepara para abrir los sectores de seguros, telecomunicaciones, ferrocarriles, electricidad y aviación civil. ${ }^{5}$

Aunado a lo anterior, China promueve la integración regional en Asia, en particular con los países de la Asociación de Naciones del Sureste Asiático (ANSEA), en la cual participan
Brunei, Camboya, Filipinas, Indonesia, Laos, Malaisia, Myanmar, Singapur, Tailandia y Vietnam. Con todos ellos, China espera completar una zona de libre de comercio. En el ámbito subregional, sus intercambios con Corea y Japón son prioritarios, lo mismo que con Rusia, Asia central y Asia septentrional. En los casos de Hong Kong, Macao y Taiwan, economías miembros de la omc, los intercambios son preferenciales. El profesor Chi no descarta que en el futuro "el espacio chino" (China continental, Hong Kong, Macao y Taiwan) se erija en una zona de libre comercio, para lo cual tendrían que seguir de común acuerdo lo que señala la omc para estos casos, incluidos aranceles preferenciales, reglas de origen, liberalización del sector bancario y de seguros, etcétera. Esto se derivaría de un proceso de integración ya en marcha, pero cuyo éxito depende de la actitud del ejecutivo de Taiwan, pues en apariencia el sector privado taiwanés vería con interés semejante prospecto dadas sus cuantiosas inversiones en China continental.

Asimismo y si bien no lo menciona el libro, la participación de China en el mecanismo de Cooperación Económica Asia Pacífico (APEC) ha entrañado también una serie de reformas y ajustes internos para facilitar el libre comercio en el ámbito de este foro. A este efecto, la Comisión Nacional de Reforma y Desarrollo asume la ejecución de cada uno de los compromisos que China adquiere - a través de su plan de acción individual-en el seno del APEC.

d) Una nueva política integral para el campo. Con cerca de 800 millones de campesinos, no sorprende que China busque medidas para aliviar la situación que en los últimos años se ha presentado en el sector rural en el país, donde irónicamente se inició el proceso de reforma y apertura impulsado por Deng Xiaoping. Acaso el principal impedimento para que los campesinos mejoren su situación se presenta en el sistema tributario que pesa sobre ellos, el cual data de 1958, cuando las condiciones del país eran por completo distintas a las que prevalecen en la actualidad. Para el profesor Chi, hay urgencia de otorgar seguri- 
dades a la propiedad de los predios rurales, a través del sistema de contratos con duración de 30 años y renovación inmediata, pero con medidas que impidan a las grandes corporaciones privadas adquirir vastas extensiones de terreno a precios por debajo del mercado (p. 173).

También habría que brindar seguridad social a los campesinos y permitirles formar organizaciones de afiliación voluntaria para que, asociados en cooperativas, negocien mejor la venta de sus productos en el mercado; se capaciten en nuevas técnicas de producción y cuenten con "una administración democrática" (p. 183). A fin de fortalecer los derechos de propiedad, el libro aboga por el derecho a la herencia y a la hipoteca, con la correspondiente expedición de certificados de usufructo como ocurre ya en las ciudades.

Por añadidura, Chi Fulin propone al gobierno chino que apoye y proteja los intereses del sector agropecuario nacional a través de aranceles racionales de forma compatible con los preceptos de la oмc (p. 188). Las ciudades, además, habrán de absorber más mano de obra campesina desempleada, pero para esto deben suprimirse las restricciones aún no del todo desmanteladas para establecer residencia permanente en cualquier punto de la geografía china. Esto permitiría acelerar el desarrollo de la infraestructura urbana y brindaría las oportunidades de trabajo que cientos de millones de campesinos no encuentran en sus comunidades.

e) Tópicos recientes en infraestructura y el sector servicios. En estos sectores se requiere el establecimiento de un nuevo sistema de administración de las empresas, así como medidas que alienten la formación de compañías privadas. China: the New Stage of Reform apuesta por una reforma legal que desmantele los monopolios, introduzca la competencia y administre el mercado a través de normas y disposiciones (p. 206), tanto en el sector de infraestructura como en el de servicios específicamente. Por lo tanto, cada empresa deberá participar en el mercado bursátil mediante la emisión de acciones. Este proceso debiera empezar, indica el profesor Chi, en los sectores de transporte, telecomunicaciones y energía que reúnan las condiciones necesarias (p. 219). En el resto de la economía este proceso podría introducirse en etapas sucesivas. Todas estas medidas promoverían una mayor competitividad, evitarían la "alianza" entre gobierno y empresas, y presentarían un marco más atractivo para las inversiones. ${ }^{6}$ Sólo así cabría poner en práctica un mecanismo de precios basado en las condiciones del mercado. Una apertura semejante del mercado contaría por fuerza con un nuevo sistema de supervisión gubernamental en el contexto de una economía de mercado. De no producirse estos cambios, los sectores de infraestructura y servicios corren el riesgo de sumirse en el rezago (p. 233).

f) La formación del sistema empresarial y el plan para hacer de los empleados copropietarios de las empresas. Si bien el compromiso de China con la omc ofreció establecer una economía de mercado hacia 2010 , la dirigencia china ha tomado medidas para que esto ocurra en 2007 (p. 283). Pese a todo, Chi Fulin reconoce que las políticas gubernamentales deben superar el estancamiento de la reforma en ciertas áreas y su lento progreso en otras tantas.

Asimismo, se ha vuelto ineludible el establecimiento de un nuevo sistema de administración interna de las empresas privadas, para promover la cultura y la ética empresariales. Junto a estas medidas debe promoverse que los empleados sean al mismo tiempo copropietarios de las empresas a través de la adquisición de acciones que participan en el mercado bursátil, lo cual constituye "un requisito para las empresas en desarrollo y una tendencia general de las empresas modernas" ( $p$. 287). La medida busca al mismo tiempo fortalecer la lealtad de los empleados para con la empresa, algo que de manera ejemplar ha logrado Microsoft, donde $80 \%$ de los trabajadores poseen acciones de la compañía. En el caso de las empresas estatales que opten por este esquema, adicionalmente se producirían otros efectos positivos: la liberación de recursos del 
Estado y el mejoramiento de la estructura de distribución del ingreso, pero se requeriría hacerlo de manera ordenada y con un replanteamiento completo de los ordenamientos que rigen la administración de las empresas en China.

El autor hace notar que en los últimos veinte años se ha desarrollado en China un conjunto de empresarios pioneros en el sector privado el país. Sin embargo, no se cuenta con un verdadero sistema empresarial (p. 292). Por lo que se refiere a las empresas paraestatales, alerta sobre "el síndrome de los 59 años de edad", cuando algunos altos directivos de las empresas del Estado están a punto de jubilarse e incurren en algún tipo de malversación de fondos, en un fenómeno de corrupción que parece vincularse a la falta de adecuados salarios y prestaciones jubilatorias. Por todos estos motivos, debe promoverse una cultura y una ética empresarial, mediante incentivos, una evaluación del mercado y una mejor administración al interior de las empresas.

Para concluir, debe destacarse que China: the New Stage of Reform reflexiona sobre los aspectos más relevantes de esta etapa del proceso de reforma y apertura en China, con un afán crítico y altamente propositivo que no se permite tregua ni reposo. Sería de esperarse que en el futuro cercano otros académicos chinos analizaran, con el mismo espíritu crítico y propositivo, temas como los mecanismos para fijar el tipo de cambio del renminbí y la protección al medio ambiente en China. Hasta ahora el tipo de cambio de la moneda nacional no está determinado por el libre juego de la oferta y la demanda, como ocurre por lo regular en las economías de mercado.

La protección al medio ambiente, a pesar de los esfuerzos recientes, padece rezagos preocupantes. Se trata de temas muy sensibles, pues un tipo de cambio realista del renminbí podría elevar los precios de las exportaciones chinas, con una consecuente pérdida de competitividad; o, por el contrario, generar una espiral inflacionaria difícil de predecir. En cuanto a la protección al medio ambiente, al parecer se vuelve impostergable la aplicación estricta de los ordenamientos respectivos por parte de las autoridades, al tiempo que las empresas chinas no tendrán más remedio que sumar a sus costos de producción la tecnología anticontaminante que se requiera, con el correspondiente aumento de precios en sus productos y servicios. En este aspecto, China parece debatirse entre acelerar el deterioro ambiental, en aras de mantener un crecimiento económico vigoroso, o, por el contrario, acelerar la protección ambiental y afrontar sus costos. La decisión que se tome, en uno u otro sentido, generará consecuencias de alcance planetario. $^{7}$

A lo anterior sólo cabe añadir que los ensayos que componen este libro tratan de modo recurrente cada uno de los tópicos estudiados y dejan entrever la evolución de cada uno de ellos a lo largo de los últimos tres o cuatro años. El mayor mérito del profesor Chi Fulin radica en que sus propuestas no discurren en un vago ejercicio de especulación, pues se trata de documentos en extremo propositivos que el gobierno chino ha tomado en cuenta en sus decisiones para profundizar el proceso de reforma y apertura; atender los efectos indeseados de este proceso, y plantearse con previsión estratégica los retos futuros para el desarrollo económico de China.

\section{Notas}

1 Para conocer en detalle el proceso de ingreso de China a la омс y los ajustes a la estrategia del desarrollo chino, ver Wang Mengkui (ed.) China: Accession to the WTO and Economic Reform, Foreign Language Press, Pekín, China, 2002, $416 \mathrm{pp}$.

2 El "Documento No. 1", dado a conocer por el Comité Central del Partido y el Consejo de Estado, articula una serie de medidas favorables a mejorar sustancialmente la precaria situación del ingreso de los campesinos en China. Entre otras decisiones se incluyen las siguientes: acelerar la supresión de diversas cargas fiscales; incrementar los subsidios a la producción agrícola; orientar mayores inversiones al sector agropecuario, en particular infraestructura; crear nuevas partidas presupuestales para el desarrollo social en los distritos rurales. Ver el diario Renmin Ribao, 31 de enero de 2005.

3 Según datos de la Comisión Reguladora de la Banca en China, el volumen de cartera vencida de los cuatro gi- 


\section{Temas varios del Pacífico}

gantes bancarios estatales de China (el Banco de Industria y Comercio, el Banco de China, el Banco de la Construcción y el Banco Agrícola) se redujo durante 2004 , al pasar de 2.1 billones de yuanes a 1.7 billones de yuanes; es decir, de unos 256 mil millones a $207 \mathrm{mil}$ millones de dólares. Según un artículo de Tan Wei, publicado en la revista Beijing Zhou Bao, del 3 de febrero de 2005, hasta ahora sólo instituciones financieras extranjeras se han interesado por adquirir la cartera vencida de los bancos chinos.

4 En enero de 2005, China y Chile iniciaron negociaciones con miras a establecer un acuerdo de libre comercio.
$5 \mathrm{Al}$ anunciarse a fines de enero en Pekín la apertura para que empresas extranjeras inviertan en la construcción de doce nuevas plantas nucleares entre 2005 y 2020 , el gobierno chino precisó que el $70 \%$ de los componentes de tales plantas deben ser de origen nacional. Ver Financial Times, "China demands local parts in new plants", 20 de enero de 2005.

6 A principios de 2005, el Consejo de Estado dio a conocer su decisión de terminar en definitiva con el rescate financiero de empresas paraestatales en quiebra, pues a partir de este año el destino de estas empresas quedará en manos de "las leyes y el mercado". Renmin Ribao, 3 de febrero de 2005.

7 Jared Diamond, Collapse: How Societies Chose to Fail or Succeed, Viking, 2004, 592 pp.<smiles>[AlH2]</smiles>

\section{Para consultar otros números de la revistaMéxico y la Cuenca del Pacífico, ingresar a la página de Internet:}

\section{http://publicaciones.cucsh.udg.mx/pperiod/pacifico/index.html}

